\title{
PLASMA CLOT TENSILE STRENGTH MEASUREMENT: ITS RELATION TO PLASMA FIBRINOGEN ${ }^{1}$
}

\author{
By A. I. GOLDFARB,2 I. M. TARLOV, S. BOJAR, AND A. S. WIENER \\ (From the Neurosurgical Service and the Department of Laboratories of the Jewish Hospital \\ of Brooklyn, New York)
}

(Received for publication August 14, 1942)

In the course of experimental work on the problem of autologous plasma clot suture of nerves (1), the desirability of in vitro tests of plasma clots became apparent and an instrument and method which might serve the purpose were devised. Since the procedure seemed likely to be useful to other workers, it was reported (2) while we were still accumulating the data now presented.

Methods for measuring the tensile strength of clots have been used previously. Fonio (3) centrifuged $6 \mathrm{cc}$. quantities of blood mixed with $2 \mathrm{cc}$. of 0.75 per cent $\mathrm{MgSO}_{4}$ to retard clotting, allowed spontaneous clotting of the supernatant plasma, then cut the plasma clot free of the cellular portion below. After compressing the clot in a special press to a $0.5 \times 1.0 \mathrm{~cm}$. disc, it was fixed in ether and then clipped above and below in its shorter dimension. Weights were then added until the clot broke and the maximal weight held recorded. The tensile strength of such fibrin discs was found to vary in individuals, the normal range being from about 250 to 350 grams. In diseased individuals, he found that the values obtained were often greater or less than the normal (4). He did not attempt to correlate this variation with any property or constituent of the blood. Kristenson (5) used a slightly different technique; he did not add any anticoagulant and allowed the clot to retain its natural shape. Clots were formed from chilled plasma, in test-tubes of uniform bore, and fixed in ether. He suggested that variations in clot tensile strength are dependent on varying amounts of fibrinogen present as well as on other factors.

In the present paper, some factors affecting the tensile strength of plasma clots have been inves-

1 This study was aided by a grant from the Committee on Scientific Research of the American Medical Association.

2 Fellow in Surgical Research. tigated, using a technique somewhat modified from that described by Kristenson. An attempt has been made to avoid objections such as can be raised against the work of Fonio and of Kristenson, by omitting the use of any fixative, by testing the clots in triplicate or quadruplicate, and by examining a larger number of specimens in order to attain at least minimal statistical validity.

\section{METHOD}

The method used by us consists essentially of allowing coagulation of $1 \mathrm{cc}$. of plasma to take place in test-tubes of uniform bore $(0.75 \mathrm{~cm}$. in diameter $)$, at $37.5^{\circ} \mathrm{C}$., in a water bath. No anticoagulant was added (unmodified plasma), premature clotting being prevented by drawing the blood into a chilled, oiled syringe and immediately transferring it to paraffin-lined tubes, packed in ice, for centrifugation to separate the plasma.

The clots were removed from the test-tubes by carefully rimming them with a cool platinum wire and then either enmeshing the tip of the wire in the uppermost portion or heating the tip of the wire so that the clot would adhere to it and could thus be lifted out.

The apparatus used (2) is essentially a rigid frame to which is attached a rubber-sleeved hemostat which clips the upper end of the clot and suspends it in front of a millimeter rule. A light rubber-sleeved clip grasps the lower end of the clot. To the lower clip are appended 5 or 10 gram weights, one at a time, until rupture of the clot occurs. The increase in length is measured as each weight is added.

The tensile strength is defined in this paper as the maximum weight held in grams (including the weight of the clip) before the final increment caused rupture of the clot.

\section{PRECAUTIONS}

Variability in readings obtained in testing clots, formed from the same specimen of plasma under the same conditions, is to be expected on the basis of experimental error intrinsic to the method.

Care must be taken to avoid damage to the clot when removing it from the tube or applying the clip. One's suspicion should be aroused if in the test, when the weight is applied, the rupture does not occur near the mid-point where "necking" ordinarily is maximal. When the clot is clipped, its entire width must be included because the tensile strength varies with the cross-sectional area. On the other hand, since our results show that the 
length of the clot has very little effect on the tensile strength reading, should the clot be torn when the clip is applied, there is no objection to reapplying it if enough clot remains for convenient testing. Also, in order to avoid shearing, the clot must be clipped exactly transversely, and some practice is required before one learns to apply the weights without tugging. In general, improper technique as outlined above tends to give a false low value for the tensile strength.

In most of our determinations, an interval of 15 minutes was allowed to elapse between clotting and the first test. This was done because it was not infrequently observed (especially in experiments where anticoagulant substances had been added to plasma) that the clot did not appear to have achieved what was considered its maximum stability until approximately such a period had elapsed. Thus, after clotting had progressed sufficiently at the surface to prevent deformation on tipping ("tip test"), the base of the clot might still show merely strand-like clotting and a more transparent or "fluid" appearance. When such clots were removed from the tubes, their lower parts were found to consist merely of fibrin sacs, filled with unclotted plasma. Accordingly, we deemed it advisable to make a quantitative study of the tensile strength of the clots in relation to their age. Ten series of clots were tested, in duplicate and triplicate, at the following ages: $0,3,6,9,12,15,20$, and 30 minutes, 0 representing the time when the tip test first became positive. (Older clots were not tested as it had previously been found that there was no variation among clots whose ages ranged from $1 / 2$ hour to 24 hours.) Since the clots in these experiments were prepared from plasmas from different individuals, they varied considerably in tensile strength. In order not to give undue weight to those clots with high tensile strength, when computing the average tensile strength of any given specimen at any

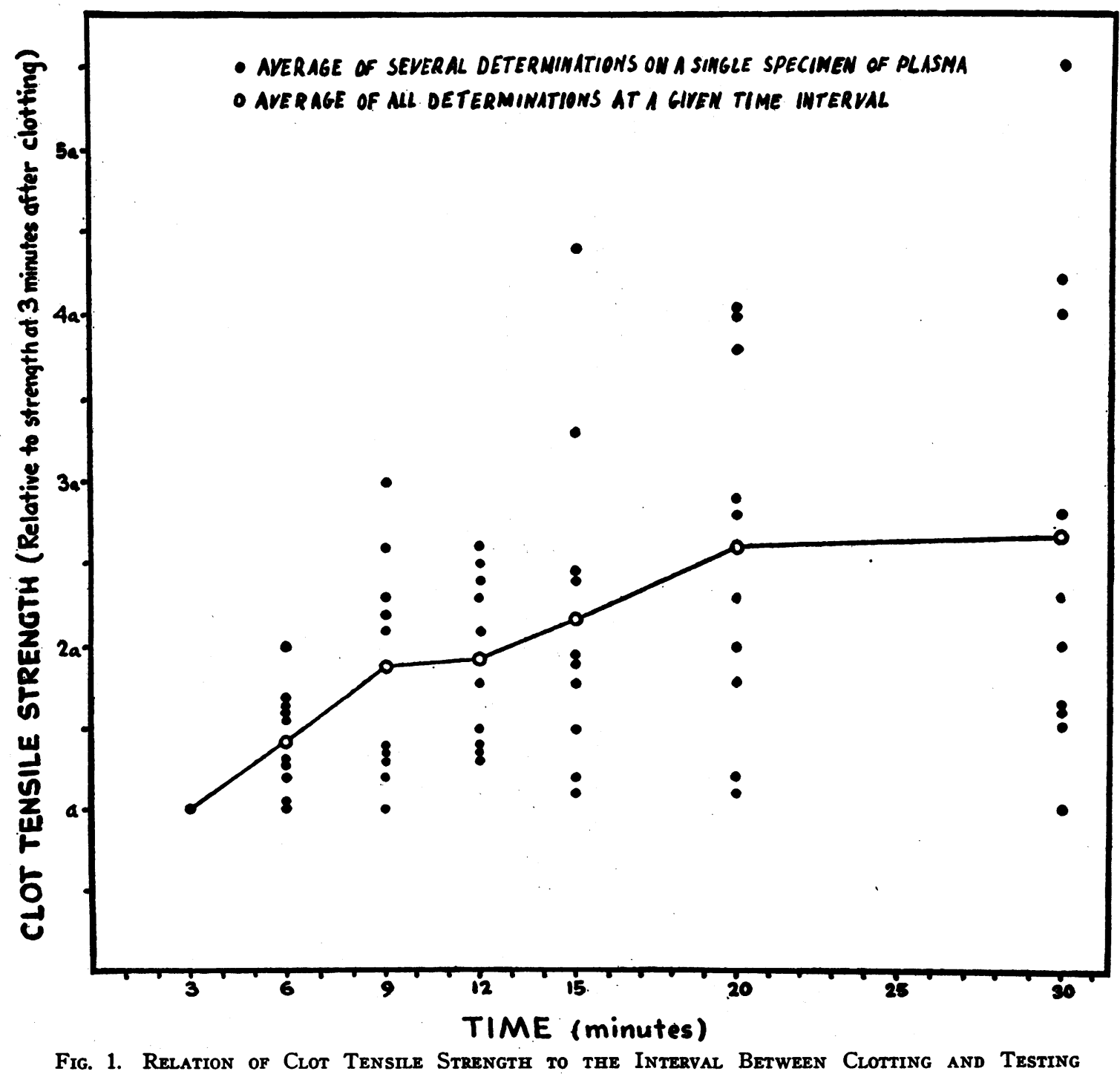


TABLE I

Plasma clot tensile strength (in grams) in 11 normal individuals

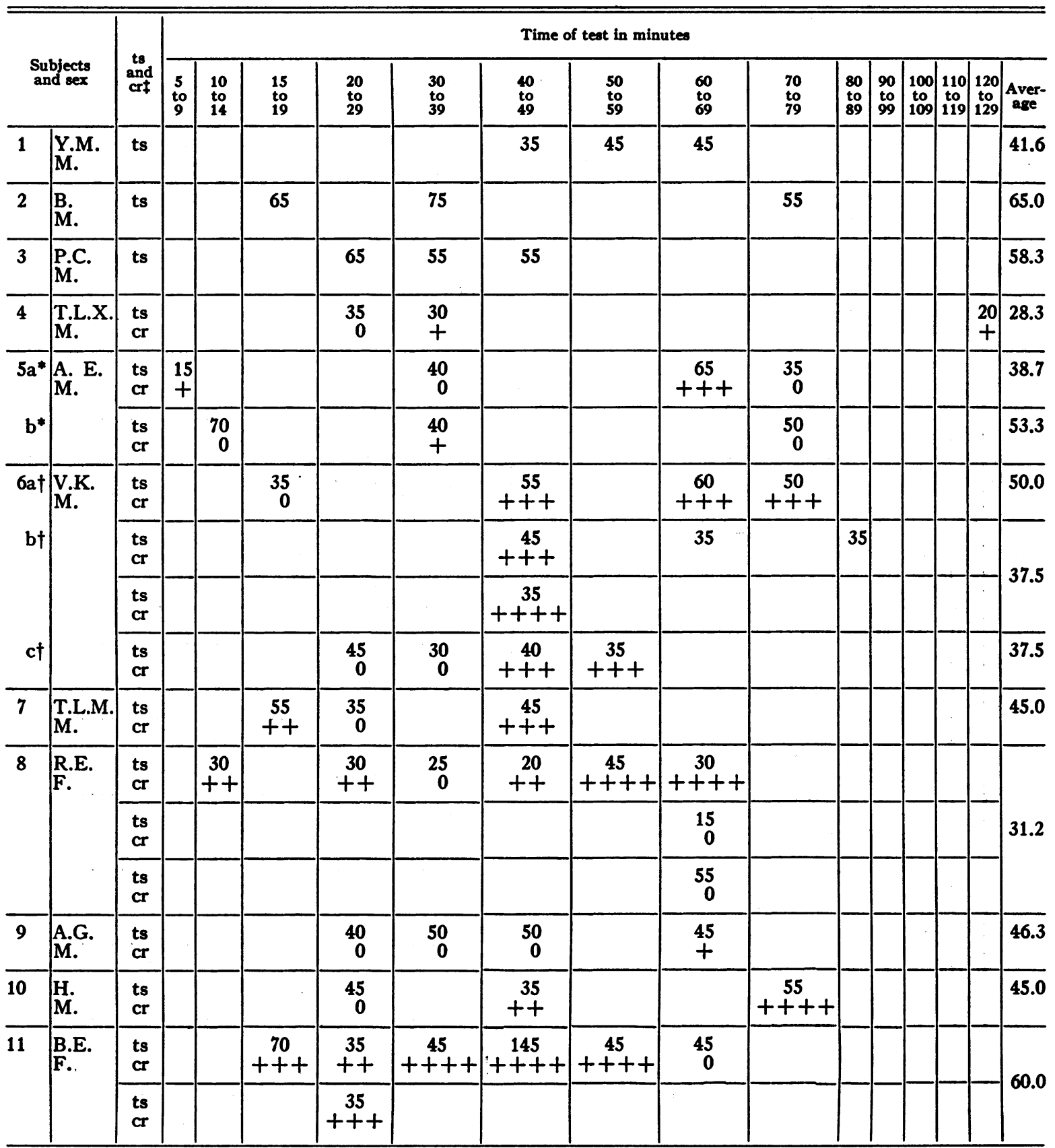

$\ddagger$ ts indicates tensile strength and $\mathrm{cr}$, clot retraction $(+$ slight, ++ moderate, +++ considerable, and ++++ marked).

* Repeat tests on same subject at interval of several days.

† Repeat tests at weekly intervals.

given time, this was expressed in relation to its strength at 3 minutes taken as a base (a). Figure 1 shows the relative increment in clot tensile strength with the age of the clot. It can be seen that there is an increase in strength until the age of the clot reaches 20 minutes, after which there is hardly any change.
RESULTS

\section{Normal variations in clot tensile strength}

Table I gives the data obtained from the study of 11 normal human subjects (of ages 6 to 53 
years). Specimens 1,4 , and 7 were from healthy young blood donors; 2,3 , and 10 were from healthy males who had undergone minor surgical procedures on the hospital ward; 5, 6, and 9 were from laboratory workers; 8 and 11 were from females studied in the Out-Patient Department and reported as free of organic disease.

The table demonstrates that in normal individuals, by this method, there is variation of clot tensile strength, but within a narrow range. The mean clot tensile strength of normals in this group is $\mathbf{4 5 . 5}$ grams. There was no apparent correlation between clot tensile strength and age or sex. This lack of correlation was substantiated by all data obtained subsequently. In the table, we have also recorded the degree of retraction of each clot tested and it can be seen that this varied considerably. There appears to be no relation between

TABLE II

Plasma fibrinogen in grams per 100 cc. plasma and clot tensile strength in grams held

\begin{tabular}{|c|c|c|c|c|c|c|c|c|c|c|}
\hline \multirow{2}{*}{$\overline{\text { Patient }}$} & \multirow{2}{*}{ Sex } & \multirow{2}{*}{$\frac{\text { Diagnoeis }}{\text { Involutional melancholia }}$} & \multicolumn{2}{|c|}{ Fibrinogen* } & \multicolumn{5}{|c|}{$\begin{array}{l}\text { Tensile strength and clot retraction } \\
\text { (quadruplicate determinations) } \dagger\end{array}$} & \multirow{2}{*}{$\begin{array}{c}\begin{array}{c}\text { Average } \\
\text { tensile } \\
\text { strength }\end{array} \\
57.5\end{array}$} \\
\hline & & & 0.27 & 0.40 & $\begin{array}{c}55 \\
\ddot{+} \ddot{+} \ddot{t}\end{array}$ & $\begin{array}{c}\quad \begin{array}{c}55 \\
\cdots \\
0\end{array} \mid \\
0\end{array}$ & $\begin{array}{c}65 \\
\cdots \cdots \\
+\cdots\end{array}$ & $\left|\begin{array}{c}55 \\
\cdots \cdots \\
+++\end{array}\right|$ & $\ldots \ldots$ & \\
\hline M. B. & $\mathbf{M}$ & Arteriosclerosis & 0.29 & & $\begin{array}{c}55 \\
\cdots \\
+\end{array}$ & $\begin{array}{c}55 \\
\cdots \\
0\end{array}$ & $\begin{array}{c}65 \\
\cdots \cdots \\
++4\end{array}$ & $\cdots \cdots \cdots$ & $\cdots \cdots$ & 58.3 \\
\hline R. S. & $\mathbf{M}$ & Inguinal hernia & 0.31 & 0.37 & $\begin{array}{c}45 \\
\cdots \cdots \\
+\end{array}$ & $\begin{array}{c}35 \\
\cdots \cdots \\
++\end{array}$ & $\begin{array}{c}50 \\
\cdots \\
+\ldots+\end{array}$ & $\begin{array}{c}55 \\
\cdots \cdots \\
+\end{array}$ & $\cdots \cdots \cdots$ & 46.2 \\
\hline M. A. & $\mathbf{M}$ & Inguinal hernia & 0.32 & & $\begin{array}{c}55 \\
\cdots \\
0\end{array}$ & $\begin{array}{c}75 \\
\cdots \\
0\end{array}$ & $\begin{array}{c}75 \\
\cdots \\
+\end{array}$ & $\begin{array}{c}35 \\
\cdots \\
0\end{array}$ & $\begin{array}{c}65 \\
\cdots \\
0\end{array}$ & 61.0 \\
\hline E. B. & $\mathbf{M}$ & $\begin{array}{l}\text { 1. Possible typhoid fever } \\
\text { 2. Possible trichinosis }\end{array}$ & 0.40 & & $\begin{array}{c}45 \\
\ldots \ldots \\
+\end{array}$ & $\begin{array}{c}55 \\
\cdots \cdots \\
++\end{array}$ & $\begin{array}{c}55 \\
\cdots \\
+\end{array}$ & $\begin{array}{c}55 \\
0 \\
0\end{array}$ & & 52.5 \\
\hline R. W. & $\mathbf{F}$ & Pulmonary tuberculosis, healed & 0.40 & 0.44 & $\begin{array}{c}65 \\
\cdots \cdots \\
+\ldots\end{array}$ & $\begin{array}{c}55 \\
\ldots \ldots \\
+\ldots+t\end{array}$ & $\begin{array}{c}75 \\
\cdots \cdots \\
+\ddot{t}+\end{array}$ & $\begin{array}{c}75 \\
\ldots \ldots \\
+\ldots+t\end{array}$ & $\cdots \cdot$ & 67.5 \\
\hline J. P. & $\mathbf{M}$ & Myelogenous leukemia & 0.42 & & $\begin{array}{c}95 \\
0 \\
0\end{array}$ & $\begin{array}{c}45 \\
\ldots \\
0\end{array}$ & $\begin{array}{c}95 \\
0 \\
0\end{array}$ & $\begin{array}{c}95 \\
\ldots \ldots \\
+\ldots\end{array}$ & & 80.0 \\
\hline M. A. & $\mathbf{F}$ & Pregnancy & 0.43 & 0.48 & $\begin{array}{c}115 \\
\cdots \\
+\end{array}$ & $\begin{array}{c}65 \\
\ldots \ldots \\
+\ldots+\end{array}$ & $\begin{array}{c}145 \\
\ldots \ldots \\
+x+\end{array}$ & $\begin{array}{c}100 \\
\ldots \ldots \\
0\end{array}$ & $\cdots$ & 106.2 \\
\hline A. $\mathbf{W}$. & $\mathbf{M}$ & Nephritis & 0.44 & 0.48 & $\begin{array}{c}55 \\
\ldots \ldots \\
+\end{array}$ & $\begin{array}{c}75 \\
\ldots \ldots \\
+t+t\end{array}$ & $\begin{array}{c}85 \\
\ldots \ldots \\
+\ldots+\end{array}$ & $\begin{array}{c}35 \\
\ldots \ldots \\
+\end{array}$ & & 62.5 \\
\hline F. $\mathbf{N}$. & $\mathbf{M}$ & Acute rheumatic fever & 0.46 & 0.63 & $\begin{array}{c}55 \\
\ldots \ldots \\
+t\end{array}$ & $\begin{array}{c}85 \\
\ldots \ldots \\
++t+\end{array}$ & $\begin{array}{c}65 \\
\ldots \ldots \\
+t\end{array}$ & $\begin{array}{c}65 \\
\ldots \ldots \\
0\end{array}$ & $\cdots$ & 67.5 \\
\hline $\mathbf{K}$. & $\mathbf{F}$ & Pregnancy & 0.50 & 0.54 & $\begin{array}{c}135 \\
\ldots \ldots \\
++4\end{array}$ & $\begin{array}{c}95 \\
\ldots \ldots \\
0\end{array}$ & $\begin{array}{c}105 \\
\ldots \\
0\end{array}$ & $\begin{array}{c}95 \\
0 \ldots \\
0\end{array}$ & & 107.5 \\
\hline C. 0 . & $\mathbf{F}$ & Pulmonary tuberculosis & 0.505 & 0.65 & $\begin{array}{c}145 \\
\ldots \ldots \\
+\ldots+\end{array}$ & $\begin{array}{c}75 \\
\ldots \ldots \ldots \\
+\ddot{+}+\end{array}$ & $\begin{array}{c}135 \\
\ldots \ldots \\
+\ddot{+}+\end{array}$ & $\begin{array}{c}75 \\
\ldots \ldots \\
+\ldots+\end{array}$ & & 107.5 \\
\hline M. A. & $\mathbf{M}$ & Fracture of left femur & 0.525 & & $\begin{array}{c}85 \\
\ldots \ldots \\
+\ddot{t}+\end{array}$ & $\begin{array}{c}85 \\
\ldots \ldots \\
+\ldots+t\end{array}$ & $\begin{array}{c}75 \\
\ldots \ldots \\
+\ddot{t}+\end{array}$ & $\ldots \ldots$ & $\cdots$ & 81.6 \\
\hline
\end{tabular}


TABLE II-C Continued

\begin{tabular}{|c|c|c|c|c|c|c|c|c|c|c|}
\hline Patient & Sex & Diagnosis & Fibrin & ogen* & & $\begin{array}{l}\text { ensile stren } \\
\text { (quadruplic }\end{array}$ & $\begin{array}{l}\text { gith and cl } \\
\text { cate detern }\end{array}$ & $\begin{array}{l}\text { ot retracti } \\
\text { ninations) }\end{array}$ & & $\begin{array}{l}\text { Average } \\
\text { tensile } \\
\text { strength }\end{array}$ \\
\hline L. L. & $\mathbf{M}$ & Adenocarcinoma, hepatic flexure & 0.55 & & $\begin{array}{c}105 \\
\cdots \cdots \cdots \\
+++\end{array}$ & $\begin{array}{c}85 \\
\cdots \cdots \\
++++\end{array}$ & $\begin{array}{c}105 \\
\cdots \cdots \\
+++\end{array}$ & $\begin{array}{c}95 \\
\ldots \ldots \\
++++\end{array}$ & & 97.5 \\
\hline S. S. & $\mathbf{M}$ & Acute rheumatic fever & 0.56 & & $\begin{array}{c}175 \\
\cdots \cdots \\
+++\end{array}$ & $\begin{array}{c}95 \\
\ldots . \cdots \\
+++\end{array}$ & $\begin{array}{c}155 \\
\ldots \ldots \\
+++\end{array}$ & $\begin{array}{c}95 \\
\ldots \ldots \\
+++\end{array}$ & & 130.0 \\
\hline A. A. & $\mathbf{M}$ & Inguinal hernia & 0.57 & & $\begin{array}{c}75 \\
\ldots \ldots \\
++\end{array}$ & $\begin{array}{r}65 \\
\cdots \cdots \\
++++\end{array}$ & $\begin{array}{c}75 \\
\ldots \ldots \\
+++\end{array}$ & $\begin{array}{c}65 \\
\ldots \ldots \\
+++\end{array}$ & & 70.0 \\
\hline M. C. & $\mathbf{M}$ & Carcinomatosis & 0.585 & & $\begin{array}{c}165 \\
\ldots \ldots \\
+++\end{array}$ & $\begin{array}{c}85 \\
0 \\
0\end{array}$ & $\begin{array}{c}155 \\
\ldots \ldots \\
+++\end{array}$ & $\begin{array}{c}145 \\
\ldots \cdots \\
+++ \\
\end{array}$ & & 137.5 \\
\hline P. C. & $\mathbf{M}$ & Carcinoma of rectum & 0.595 & 0.79 & $\begin{array}{c}145 \\
\ldots \cdots \\
+++ \\
\end{array}$ & $\begin{array}{c}65 \\
\ldots \ldots \\
0\end{array}$ & $\begin{array}{r}85 \\
\cdots \cdots \\
++++ \\
\end{array}$ & $\begin{array}{c}105 \\
\ldots \cdots \\
+++\end{array}$ & $\begin{array}{c}95 \\
\ldots \ldots\end{array}$ & 99.0 \\
\hline C. B. & $\mathbf{F}$ & Retroperitoneal malignancy & 0.64 & & $\begin{array}{c}155 \\
\ldots \ldots \\
++ \\
\end{array}$ & $\begin{array}{c}85 \\
\ldots \ldots \\
+++ \\
\end{array}$ & $\begin{array}{r}95 \\
\ldots \ldots \\
+++ \\
\end{array}$ & $\begin{array}{c}105 \\
\ldots \ldots \\
++ \\
\end{array}$ & & 110.0 \\
\hline K. B. & $\mathbf{M}$ & Pulmonary carcinoma & 0.675 & & $\begin{array}{c}155 \\
\ldots \cdots \\
+++ \\
\end{array}$ & $\begin{array}{c}135 \\
\ldots \cdots \\
+++ \\
\end{array}$ & $\begin{array}{r}85 \\
\ldots \ldots \\
+++ \\
\end{array}$ & $\begin{array}{r}95 \\
\ldots \ldots \\
+++ \\
\end{array}$ & & 117.5 \\
\hline K. D. & $\mathbf{M}$ & Cervical adenitis & 0.67 & & $\begin{array}{c}135 \\
\ldots \ldots \\
+++\end{array}$ & $\begin{array}{c}115 \\
\cdots \cdots \\
+++\end{array}$ & $\begin{array}{r}95 \\
\ldots \ldots \\
+++ \\
\end{array}$ & $\begin{array}{c}115 \\
\cdots \cdots \\
+++\end{array}$ & & 112.5 \\
\hline M. S. & $\mathbf{M}$ & Pneumonia & 0.76 & 0.875 & $\begin{array}{c}155 \\
\cdots \cdots \\
+++\end{array}$ & $\begin{array}{c}165 \\
\cdots \cdots \\
++++\end{array}$ & $\begin{array}{c}105 \\
\ldots \ldots \\
+++\end{array}$ & $\begin{array}{c}185 \\
\ldots . . \\
+++\end{array}$ & & 152.5 \\
\hline J. D. & $\mathbf{M}$ & Pneumococcus meningitis & 0.80 & & $\begin{array}{c}225 \\
\cdots \\
0\end{array}$ & $\begin{array}{c}255 \\
0 \\
0\end{array}$ & $\begin{array}{c}195 \\
\cdots \cdots \\
0\end{array}$ & $\begin{array}{r}175 \\
\cdots \ldots \\
0\end{array}$ & & 212.5 \\
\hline J. F. & $\mathbf{M}$ & Pulmonary carcinoma with metastases & 0.85 & 1.05 & $\begin{array}{c}155 \\
\ldots . \\
++\end{array}$ & $\begin{array}{c}155 \\
\ldots \cdots \\
+++\end{array}$ & $\begin{array}{c}165 \\
\ldots \cdots \\
+++\end{array}$ & $\begin{array}{c}165 \\
\cdots \cdots \\
++\end{array}$ & & 160.0 \\
\hline A. $R$. & $\mathbf{M}$ & Pneumonia & 1.20 & & $\begin{array}{c}370 \\
\ldots \ldots \\
+\end{array}$ & $\begin{array}{c}440 \\
\cdots \cdots \\
++\end{array}$ & $\begin{array}{c}280 \\
\ldots \ldots \\
++\end{array}$ & 445 & & 383.8 \\
\hline
\end{tabular}

* The values in the two columns represent determinations on duplicate samples of plasma, handled differently, as described in the text.

,,,+++++++++++ and 0 represent different degrees of clot retraction.

the extent of retraction of a clot and its tensile strength. This is not entirely surprising if we visualize fibrin as a fibrous protein similar to fibroin, hair keratin, and muscle myosin, composed of polypeptide chains arranged roughly in parallel strands (6). If, during clot retraction, the polypeptide chain is conceived to shorten in accordion fashion due to an intra-molecular transformation, then the number of polypeptide chains in a unit cross-sectional area, upon which the tensile strength would depend, would not be affected.
Incidentally, the elastic properties of plasma clots are well illustrated by the fact that equal increments in the weight load produce approximately equal increases in the length of the clot. With normal specimens, the average increase in length with every 10 gram increment was approximately $0.2 \mathrm{~cm}$. With regard to the ability of the clot to resume its original length when the weights are removed, we have observed this to be only partial. The greater the load, the more pronounced is the disparity between the original and 


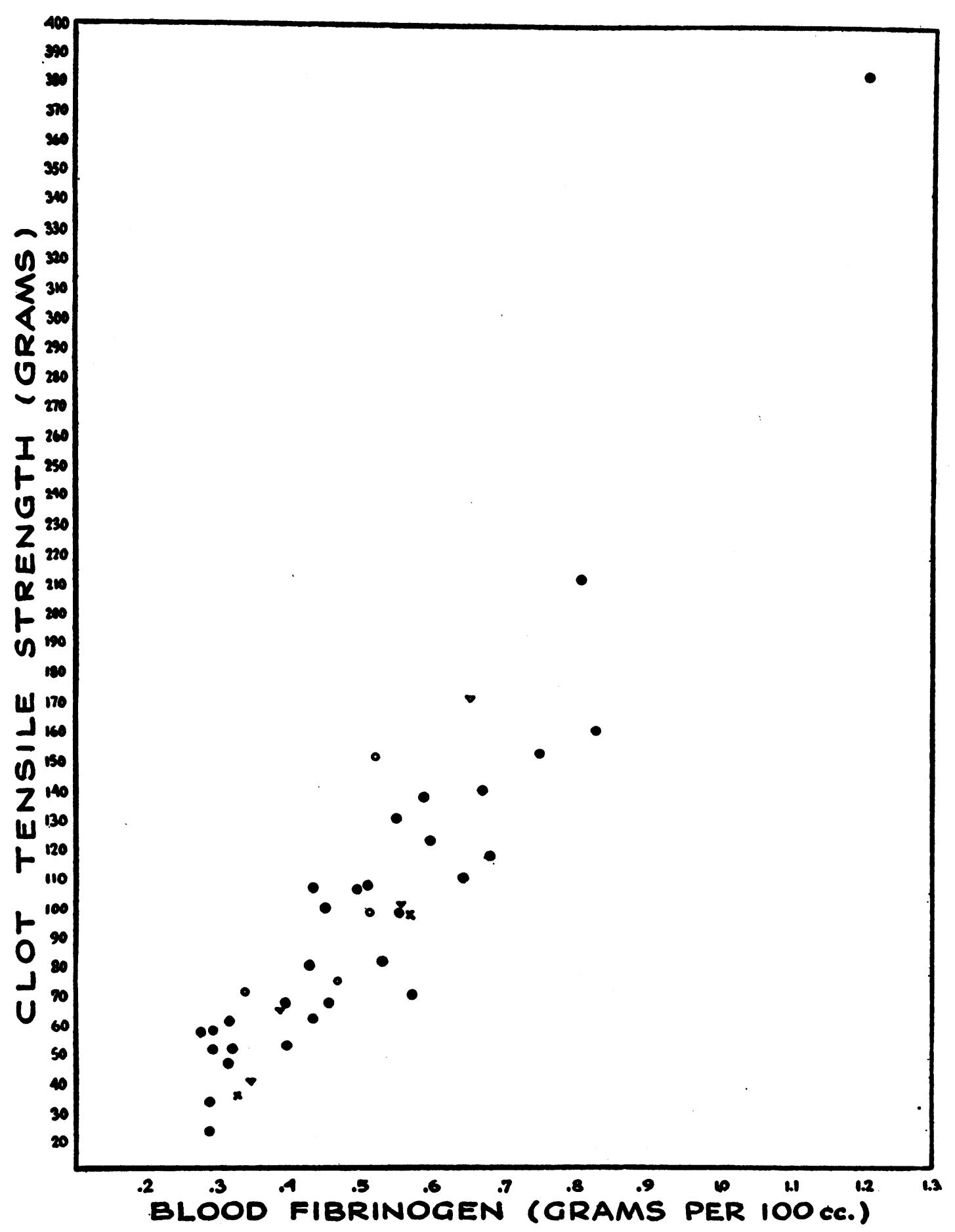

Fig. 2. Relation of Clot Tensile Strength to Blood Fibrinogen 
the recontracted lengths, with both retracted and non-retracted clots. This would indicate that the traction had produced permanent changes in the clot, one factor probably being the occurrence of irreversible intra-molecular transformations. These observations are in accord with the elastic properties that have been ascribed to protein gels in general ( 7$)$.

\section{The relation of fibrinogen content of blood plasma to the tensile strength of the clot}

The conclusions to be presented are based on experiments on 30 human subjects (Tables I and II) and 10 animals ( 2 rabbits, 4 dogs, 4 monkeys). Blood was drawn as previously described, but 10 cc. of blood were placed in a separate tube containing $10 \mathrm{mgm}$. of sodium oxalate, and the plasma fibrinogen was at once determined in duplicate by the method of Cullen and van Slyke. In almost half of the human cases, specimens of the chilled unmodified plasma were withdrawn for fibrinogen determination at the same time that the remaining portion was distributed into tubes for clotting. This was done as a control and demonstrated that the handling of the blood in the manner described resulted in no loss of fibrinogen. The values in the latter determination were somewhat higher, as expected, due to the absence of oxalate and cells, and the avoidance of water-shift from cells to plasma (cf. second column under "fibrinogen," Table II). The data for both human and animal subjects are plotted in Figure 2. Inspection of the figure demonstrates at once that a marked correlation exists between the clot tensile strength and the fibrinogen content of the plasma, as is to be expected. Indeed, the coefficient of correlation of plasma fibrinogen with the clot tensile strength, based on the observations on the 30 human subjects, was found to be very high (equal to +0.914 $\pm 0.020) .^{3}$ In fact, the fibrinogen content of the plasma could be estimated roughly from the tensile strength of the clot.

Further evidence of the dependence of tensile strength of plasma clots on the fibrinogen content was provided by the observation of Young and Medawar (8) that it is possible to strengthen the

\footnotetext{
8 Readers desirous of inspecting the correlation table showing the calculation of the coefficient of correlation may obtain a copy by writing to the authors.
}

clots prepared from cockerel plasma by increasing the fibrinogen content (Mellenby's method). This method of fortifying unmodified plasma from human beings and rabbits we have found to be difficult because the plasma frequently clots before the fibrinogen can be dissolved in it. Fortification of human and rabbit heparinized plasma is more feasible and the tensile strength of the clots formed from such plasma is greater than if no extra fibrinogen is added.

\section{DISCUSSION}

The main point demonstrated by our study is that there is a very definite correlation between the tensile strength of clots and the level of available fibrinogen in the plasma. The variation in tensile strength of clots formed from subjects with similar plasma fibrinogen levels must depend in large part on the combined experimental errors of the two methods of study. That the scatter may also be due to other factors such as variations in the amount of thromboplastic substances, calcium, and anticoagulant substances present, cannot be excluded.

As for the role of the platelets in the physical properties of the clot, it may be significant that the plasma of fowl (cockerel), whose blood contains nothing strictly analogous to the platelets of mammals, formed clots which were much less elastic. Incidentally, these clots were usually far weaker than should have been expected even when we used special methods of clamping and clipping the clots in order to prevent crushing.

\section{CONCLUSIONS}

1. The tensile strength of clots formed from normal human plasma varies within a narrow range. The variation in clot tensile strength observed in normal human beings is probably due in part to experimental error and in part to differences in the concentration of plasma fibrinogen.

2. A correlation is shown to exist in humans, monkeys, dogs, and rabbits, between clot tensile strength and the amount of fibrinogen in the plasma. The correlation coefficient between the fibrinogen content of human plasma and the tensile strength of the clot formed from that plasma was found to be $+0.914 \pm 0.020$ in a series of 30 determinations. 


\section{BIBLIOGRAPHY}

1. Tarlov, I. M., and Benjamin, B., Autologous plasma clot suture of nerves. Science, 1942, 95, 258.

2. Tarlov, I. M., Goldfarb, A. I., and Benjamin, B., A method for measuring the tensile strength and stretch of plasma clots. J. Lab. and Clin. Med., 1942, 27, 1333.

3. Fonio, A., Weiterer Beitrag zur Methodik der Untersuchung der Blutgerinnung. Schweiz. med. Wchnschr., 1921, 51, 146.

4. Fonio, A., Die Bestimmung der Prognose der Blutstillung. Arch. f. klin. Chir., 1928, 152, 459.
5. Kristenson, A., Untersuchungen uber die Elastizität des Fibrinkoagulums. Acta med. Scandinav., 1932, 77, 351.

6. Block, R. J., In Schmidt's The Chemistry of the Amino Acids and Proteins. C. C. Thomas, Springfield, III., 1938, Chapt. VII.

7. van der Dussen, A. A., and Maaskant, L., In Schmidt's The Chemistry of the Amino Acids and Proteins. C. C. Thomas, Springfield, Ill., 1938, Section III, Chapter IX.

8. Young, J. Z., and Medawar, P. B., Fibrin suture of peripheral nerves. Lancet, 1940, 2, 126. 